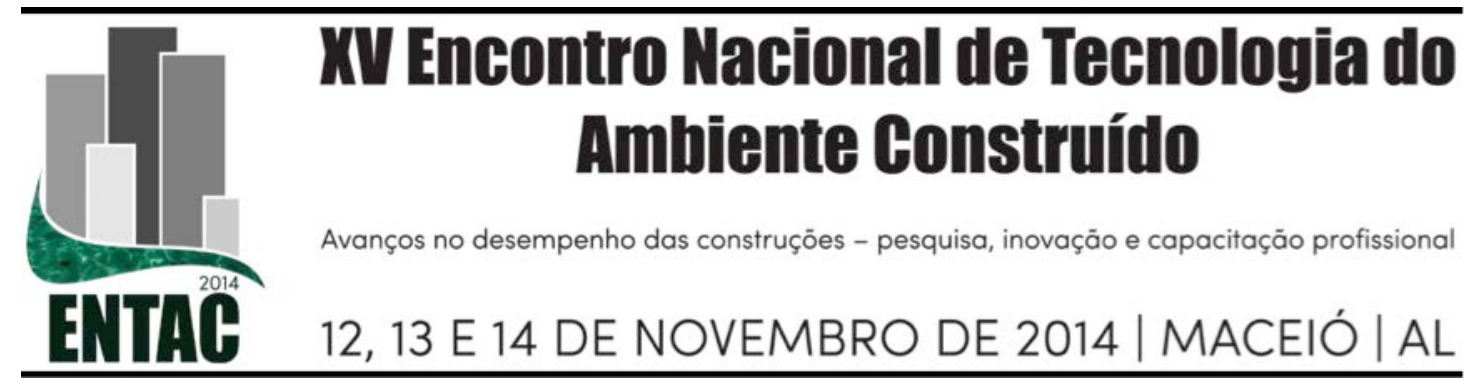

\title{
AVALIAÇÃO DOS IMPACTOS DA ABNT NBR 15575 NO CONFORTO TÉRMICO E NO CONSUMO DE ENERGIAS NAS NOVAS EDIFICAÇÕES HABITACIONAIS BRASILEIRAS
}

\author{
PEREIRA, Iraci (1); FERREIRA, Camila (2) \\ (1)UFMG, e-mail:iraci.pereira@gmail.com (2)UFOP, : ca_lilacf@yahoo.com.br
}

\begin{abstract}
RESUMO
O conjunto de normas ABNT NBR 15575/2013: Edificações Habitacionais Desempenho, em vigorar a partir de 19 de julho de 2013, estabelece os requisitos e critérios técnicos de desempenho aplicáveis às edificações habitacionais. Em termos de desempenho térmico, deve-se comprovar que a temperatura do ar interno não atinja os limites estabelecidos na Norma, em um ou dois dias do ano, o mais quente e/ou o mais frio do ano, conforme a zona bioclimática em que se situa. Contudo, tal método não possui correlação com a sensação térmica do usuário, principalmente considerando que um dia pode não ser representativo do conforto térmico do restante do ano. Além disso, a Norma apresenta algumas limitações no método de avaliação do desempenho térmico que adota. Esse artigo discute as limitações do método adotado pela Norma e demonstra que que edificações típicas de interesse social, que atendem aos critérios da Norma não são capazes de garantir condições de conforto, considerando os critérios aceitos nacionalmente da ASHRAE 55. Além disso, esse artigo calcula a demanda de energia extra causada pelo uso de ar-condicionado, nas habitações com constante desconforto térmico, mostrando o grande impacto energético que a adoção desses critérios poderá causar. $\mathrm{O}$ estudo de caso foi definido em conformidade com as características atuais do mercado imobiliário brasileiro. Constitui-se de um apartamento de cobertura voltado para a pior orientação, em uma edificação residencial multifamiliar de cinco pavimentos e quatro apartamentos por andar, totalizando 20 apartamentos. As envoltórias são de alvenaria autoportante, em de blocos de concreto estruturais, e lajes de concreto, recobertas com telhas de fibroamianto Como resultado, observou-se que os sistemas construtivos que atendem aos critérios da Norma não garantem condições de conforto aos usuários na maior parte das zonas bioclimáticas, o que pode causar um elevado consumo de energia elétrica nessas edificações.
\end{abstract}

Palavras-chave: NBR15575, Desempenho térmico, conforto térmico, eficiência energética.

\section{ABSTRACT}

The collection of standards ABNT NBR 15575/2013: Dwelling Buildings - Performance in effect from July 19, 2013, establishes the technical requirements and performance criteria applicable to the residential buildings and has the characteristics establish the responsibilities of each of those involved.. In terms of thermal performance, it must be 
proved that the temperature of the indoor air does not reach the limits in the Standard, in one or two days of the year, the hottest and/or coldest of the year, according to bioclimatic zone where is located. However, this method has no correlation with the thermal sensation user, especially considering that one day may not be representative of the thermal comfort of the rest of the year. Furthermore, the Standard introduces some limitations in the method of evaluating the thermal performance that adopts. This paper discusses the limitations of the method adopted by Standard and demonstrates that typical buildings of social interest, which meet the criteria of the Standard are not able to ensure comfort conditions, considering the nationally accepted criteria of ASHRAE 55. Moreover, this article calculates the consequent demand for extra energy use of air conditioning in dwellings with constant thermal discomfort, featuring the large energy impact that the adoption of these criteria may cause. The case study was defined according to the current characteristics of the Brazilian real estate market. It consists of a penthouse apartment facing the worst orientation in a multifamily residential building of five floors and four apartments per floor, a total of 20 apartments. The envelopes are self supporting masonry, structural concrete blocks and concrete slabs, covered with fiber cement tiles. The results show the the building systems that meet the criteria of the Standard do not guarantee the comfort of the users, in most of the bioclimatic zones, and can cause high energy consumption for air conditioning.

Keywords: NBR15575, thermal performance, thermal comfort, energy efficiency.

\section{INTRODUÇÃO}

Esse artigo é a continuação de um trabalho de avaliação dos parâmetros de desempenho térmico da Norma NBR15.575 (2013) frente aos sistemas construtivos e tipologias mais utilizadas nas construção civil brasileira. No primeiro momento, em 2012, os autores abordaram o desempenho de habitações unifamiliares (Ferreira; Pereira, 2012). Agora, aborda-se o desempenho de habitações multifamiliares - prédios, voltados para a classe média brasileira, provavelmente, a tipologia de construção mais usual da construção civil brasileira. Esse artigo parte da tese de que os critérios da Norma não são os mais adequados para se avaliar o desempenho térmico dos sistemas construtivos e também não são capazes de avaliar o conforto térmico do usuário. Dessa forma, a baixa qualidade térmica das edificações em construção no país poderá impactar em um futuro próximo, a demanda pela compra e uso de sistemas de ar condicionado.

Existe hoje a necessidade de construção de habitações de interesse social visando suprir o déficit habitacional brasileiro, estimado em 5,5 milhões de unidades (BRASIL, 2004). Dentre as medidas governamentais para combater o déficit habitacional estão medidas relacionadas com o Programa de Aceleração do Crescimento (PAC), que engloba um conjunto de políticas econômicas com prioridades de investimento em infraestrutura, e o programa habitacional Minha Casa, Minha Vida com previsão de construção de 1 milhão de moradias. Diante desta realidade, há a demanda de produção de habitações em larga escala, favorecendo assim o uso de sistemas construtivos rápidos e econômicos, além da elaboração de projetos padronizados para todo o território nacional. Contudo, é preciso considerar o impacto de tais soluções no desempenho térmico da edificação. A adoção de uma mesma tipologia de projeto e sistema construtivo para localidades em condições climáticas diversas pode ocasionar problemas térmicos na edificação.

Além disso, os sistemas construtivos dessas edificações caracterizam-se pelo emprego de camadas finas de materiais de alta condutibilidade, como o concreto, por exemplo. $\mathrm{O}$ objetivo é assegurar leveza e estabilidade estrutural aliados à rapidez na construção e 
baixos custos. No entanto, essas mesmas características físicas podem conduzir a um desempenho térmico inferior. Por isso, é de grande relevância a análise do comportamento térmico dos sistemas construtivos utilizados nessas edificações, visando a garantia de maior conforto de seus usuários e menor consumo de energia para condicionamento artificial das edificações.

Assim, o objetivo desse artigo é comparar o desempenho de uma edificação típica brasileira utilizando os critérios da Norma 15.575 e um critério de conforto, a ASHRAE 55 (2004) e estimar qual o consumo que esta edificação poderá ter, caso utilize um ar condicionado nos horários em que o usuário experimenta desconforto térmico.

\section{FUNDAMENTAÇAO}

A Norma ABNT NBR 15575 (2013) determina critérios para se avaliar o desempenho dos diferentes sistemas existentes em uma edificação residencial. Inicialmente, a Norma se limitava a edificações com no máximo cinco pavimentos, mas esse limite foi retirado nos quesitos, uma vez que o número de pavimentos não apresenta implicação. No que concerne ao desempenho térmico, a ABNT NBR 15.575 (2013) estabelece que a edificação deva atender às exigências de desempenho térmico de acordo com 0 comportamento interativo entre áreas externas, cobertura e piso, considerando o zoneamento bioclimático estabelecido na ABNT NBR 15220-3 (2005). São três os procedimentos de avaliação: simplificado (prescritivo), simulação ou medição. No procedimento simplificado verifica-se o atendimento de requisitos e critérios para os sistemas de vedação conforme estabelecido na ABNT NBR 15.575-4 (2013) e para os sistemas de cobertura conforme a ABNT NBR 15.575-5 (2013), referentes às características termofísicas de transmitância e capacidade térmica. Já no procedimento por simulação os requisitos e critérios estabelecidos na ABNT NBR 15.575-1 (2013) por meio de simulação computacional do desempenho térmico global do edifício. E, por fim, o procedimento de medição verifica os requisitos e critérios estabelecidos na ABNT NBR 15.575-1 (2013) por meio de medições a serem realizadas na própria edificação ou em protótipos construídos (ABNT, 2013).

A avaliação global do desempenho térmico de edificações por meio de simulação computacional e por medição possui dois requisitos: as exigências de desempenho no verão e no inverno. Para o verão, a edificação deve apresentar condições térmicas em seu interior equivalentes ou melhores às do ambiente externo, à sombra para o dia típico do período. Para o inverno, a edificação deve apresentar condições térmicas em seu interior melhores às do ambiente externo, no seu dia típico (ABNT, 2013). Nessa pesquisa, é avaliada apenas a condição de verão, pois o foco dessa pesquisa é o impacto na demanda do ar condicionado.

\section{MATERIAIS E MÉTODO}

\subsection{Objeto de estudo}

Em conformidade com as características atuais do mercado imobiliário brasileiro de construção, o estudo de caso foi definido como uma edificação residencial multifamiliar de cinco pavimentos e quatro apartamentos por andar, totalizando 20 apartamentos. Cada apartamento é composto por cinco cômodos (dormitório 1, dormitório 2, banheiro, sala, cozinha e área de serviço), conforme é mostrado na Figura 1. 
Figura 1 Objeto de Estudo: (A) perspectiva da edificação; (B) planta do pavimento tipo.

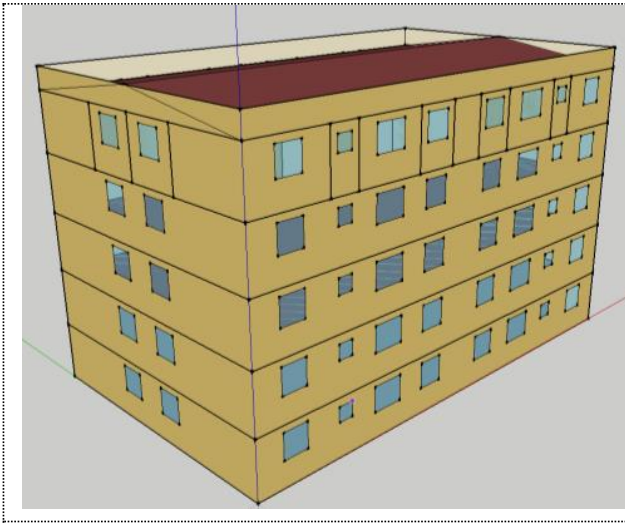

(A)

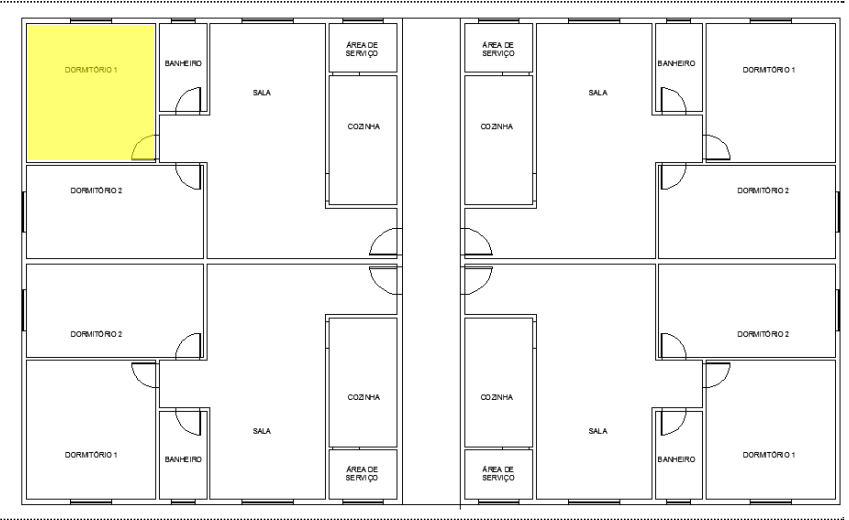

(B)

Os ambientes possuem pé direito de $2,70 \mathrm{~m}$. O cômodo considerado nas simulaçoes é sempre o com pior orientação (destacado em amarelo), no último pavimento, conforme a NBR15.574, ou seja, o quarto com orientaçao norte e oeste.

\subsection{Climas estudados}

Foram selecionadas oito cidades brasileiras, uma para cada Zona Bioclimática, ZB, definida na NBR 15.220-3 (2005). As cidades escolhidas são Maringá (ZB1), Santa Maria (ZB2), Belo Horizonte (ZB3), São Carlos (ZB4), Guaramiranga (ZB5), Barra (ZB6), Palmas (ZB7), João Pessoa (ZB8). As cidades escolhidas e sua localização são apresentados no Quadro 1.

Quadro 1 - Cidades escolhidas para o estudo e sua localização

\begin{tabular}{|c|l|c|c|c|c|c|}
\hline ZB & Cidade & UF & Latitude & Longitude & Altitude & Koppen \\
\hline 1 & Maringá & PR & $-23,4$ & $-51,91$ & 542 & Cfa \\
\hline 2 & Santa Maria & RS & $-29,7$ & $-53,7$ & 95 & Cfa \\
\hline 3 & Belo Horizonte & MG & $-19,93$ & $-43,93$ & 908 & Aw \\
\hline 4 & São Carlos & SP & $-21,96$ & $-47,86$ & 856 & Cfa \\
\hline 5 & Guaramiranga & CE & $-4,28$ & -39 & 870,67 & As \\
\hline 6 & Barra & BA & $-11,08$ & $-43,16$ & 401,58 & As \\
\hline 7 & Palmas & TO & $-10,19$ & $-48,3$ & 288 & Aw \\
\hline 8 & João Pessoa & PB & $-7,1$ & $-34,87$ & 7 & As \\
\hline
\end{tabular}

A NBR 15.575 estabelece um dia típico a ser simulado, cujos parâmetros para algumas cidades estão parcialmente descritos nos anexos da Norma. Além disso, o texto recomenda que esses dados devem ser atualizados. Devido à ausência de dados no texto da Norma para a maior parte das cidades escolhidas, optou-se por utilizar dados extraídos das Normais Climatológicas. O Quadro 2 apresenta as propriedades térmicas do ar inseridas no EnergyPlus para definição do Design Day de verão

\section{Quadro 2 - Dados climáticos utilizados no EnergyPlus para definição do Design Day de verão}




\begin{tabular}{|l|c|c|c|c|c|c|}
\hline \multicolumn{1}{|c|}{ Cidade } & ZB & $\begin{array}{c}\text { Tar máx } \\
\left({ }^{\circ} \mathbf{C}\right)\end{array}$ & $\begin{array}{c}\text { Amplitude } \\
\left({ }^{\circ} \mathbf{C}\right)\end{array}$ & TBU $\left({ }^{\circ} \mathbf{C}\right)$ & $\begin{array}{c}\text { Veloc. ar } \\
(\mathbf{m} / \mathbf{s})\end{array}$ & $\begin{array}{c}\text { Direção do } \\
\text { vento }\end{array}$ \\
\hline Maringá & 1 & 34 & 10,6 & 26,18 & 1,63 & $\mathrm{NE}$ \\
\hline Santa Maria & 2 & 28,8 & 11,3 & 25,98 & 2,93 & $\mathrm{SE}$ \\
\hline Belo Horizonte & 3 & 25,9 & 9,8 & 24 & 1,42 & $\mathrm{E}$ \\
\hline São Carlos & 4 & 35,2 & 9,7 & 24,6 & 3,14 & $\mathrm{E}$ \\
\hline Guaramiranga & 5 & 28 & 8,1 & 23,27 & 1,98 & SE \\
\hline Barra & 6 & 30,4 & 6 & - & - & - \\
\hline Palmas & 7 & 30,4 & 15,9 & - & 2,07 & SE \\
\hline João Pessoa & 8 & 30,5 & 7 & 27,44 & 2,77 & SE \\
\hline
\end{tabular}

\subsection{O desempenho térmico conforme a NBR 15.575}

A NBR 15.575-1: 2013 estabelece três níveis de desempenho térmico: mínimo (M); intermediário (I); e superior (S), a partir do valor máximo diário da temperatura do ar interior de recintos de permanência prolongada (condição de verão) e dos valores mínimos diários de temperatura do ar interior de recintos de permanência prolongada (condição de inverno). Os níveis estabelecidos são apresentados nos Quadros 3 e 4.

Quadro 3 - Critérios de avaliação de desempenho térmico para verão

\begin{tabular}{|c|c|c|}
\hline \multirow{2}{*}{$\begin{array}{c}\text { Nível de } \\
\text { desempenho }\end{array}$} & \multicolumn{2}{|r|}{ Critério } \\
\hline & Zonas 1 a 7 & Zona 8 \\
\hline $\mathrm{M}$ & Ti,max $\leq$ Te,max & Ti,max $\leq$ Te,max \\
\hline $\mathrm{I}$ & $\mathrm{Ti}, \max \leq\left(\mathrm{Te}, \max -2^{\circ} \mathrm{C}\right)$ & Ti,max $\leq\left(\mathrm{Te}, \max -1^{\circ} \mathrm{C}\right)$ \\
\hline $\mathrm{S}$ & $\mathrm{Ti}, \max \leq\left(\mathrm{Te}, \max -4^{\circ} \mathrm{C}\right)$ & $\begin{array}{c}\mathrm{Ti}, \max \leq\left(\mathrm{Te}, \max -2^{\circ} \mathrm{C}\right) \text { e } \mathrm{Ti}, \min \leq(\mathrm{Te}, \min \\
\left.+1{ }^{\circ} \mathrm{C}\right)\end{array}$ \\
\hline
\end{tabular}

Fonte: NBR 15.575-1 (ABNT, 2013).

Quadro 4 - Critérios de avaliação de desempenho térmico para inverno

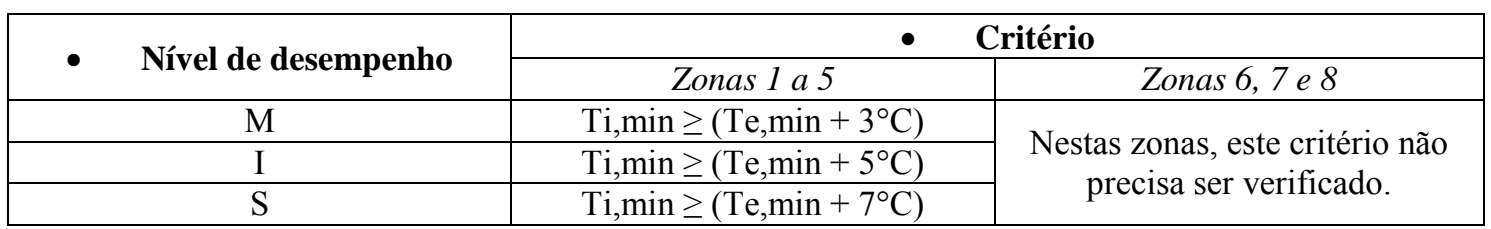

Fonte: NBR 15.575-1 (ABNT, 2013).

\subsection{A avaliação de conforto térmico pela ASRHAE 55}

Para ambientes naturalmente climatizados, com janelas cuja abertura pode ser controlada pelos usuários, a AHSRAE Standart 55 (2010) propõe a utilização de um modelo adaptativo, no qual a temperatura de conforto é função da temperatura do ar externa. Outro critério para utilização do modelo adaptativo é que os usuários estejam realizando atividades próximas às consideradas sedentárias, com taxas metabólicas entre 1,0 a 1,3 met. As temperaturas operativas internas permitidas para espaços que atendam a esses critérios, podem ser determinadas a partir da Figura 2. Esta figura inclui dois conjuntos de limites de temperatura operativa: um para $80 \%$ de aceitabilidade e um para $90 \%$ de aceitabilidade. Os limites de aceitabilidade de $80 \%$ são para aplicações típicas e deve ser usada quando outra informação não está disponível. Podem ser utilizados os limites de aceitabilidade de $90 \%$ quando um padrão mais elevado de conforto térmico é desejado. 


\section{Figura 2 - Temperatura operativa aceitável para espaços naturalmente condicionados}

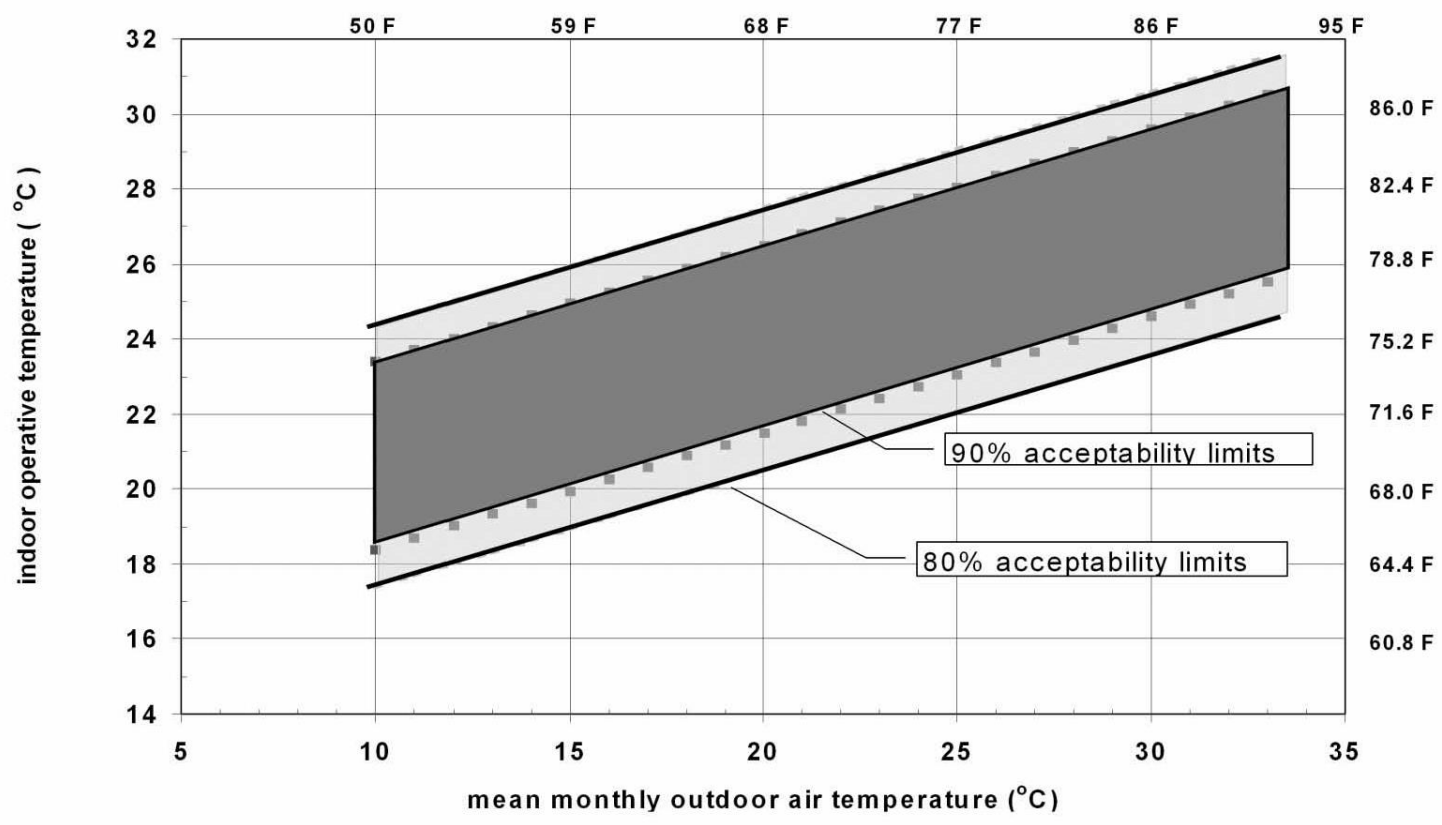

Fonte: ASHRAE, 2010

\subsection{O consumo do ar condicionado}

Nessa pesquisa, o consumo médio de energia do ar condicionado das cidades é realizado utilizando o software EnergyPlus, desenvolvido e distribuído pelo Departamento de Energia dos EUA. O software foi escolhido por ser capaz de simular considerando ventilação natural e o uso de ar condicionado, em uma mesma edificação e porque o programa realiza a avaliação do conforto térmico segundo ASHRAE Standard 55.

Em todas as cidades, foi inserido um sistema de ar condicionado Split, por ser o modelo mais vendido no Brasil (85\%) para usuários de pequeno porte. Adotou-se um valor de COP de 2,7, valor intermediário, considerando a idade dos equipamentos existentes no setor. Também foi inserida a ocupação de duas pessoas no ambiente de pior orientação. Nos demais ambientes, manteve-se a taxa de ventilação constante e sem ocupação.

Inicialmente, foi realizado uma simulação com o ar condicionado desligado e com a ventilação ocorrendo de modo constante, para se determinar os horários em que o usuário sentia desconforto por calor, conforme o critério de $80 \%$ de aceitabilidade da ASHRAE. Em seguida, uma nova simulação foi realizada, considerando o acionamento do Split apenas nesses horários de desconforto. Nos outros horários, há ventilação natural, por ser essa a melhor correspondência com o padrão de comportamento do usuário brasileiro.

\section{RESULTADOS}

A variação da temperatura do ar conforme os critérios estabelecidos na NBR-15575 é apresentada na Figura 2, onde são mostrados as curvas de temperatura interna e externa obtidos pela simulação com o EnergyPlus, para o dia de projeto de verão. Pode-se observar que em todas as cidades estudadas, a temperatura do ar interna é significativamente inferior à temperatura do ar externa, no horário mais quente do dia. 
Por essa razão, em todos os climas estudados o desempenho é Superior, conforme os critérios da NBR 15.575.

Figura 2 - Temperatura do ar interna e externa, para o dia de projeto de verão, para as cidades estudadas

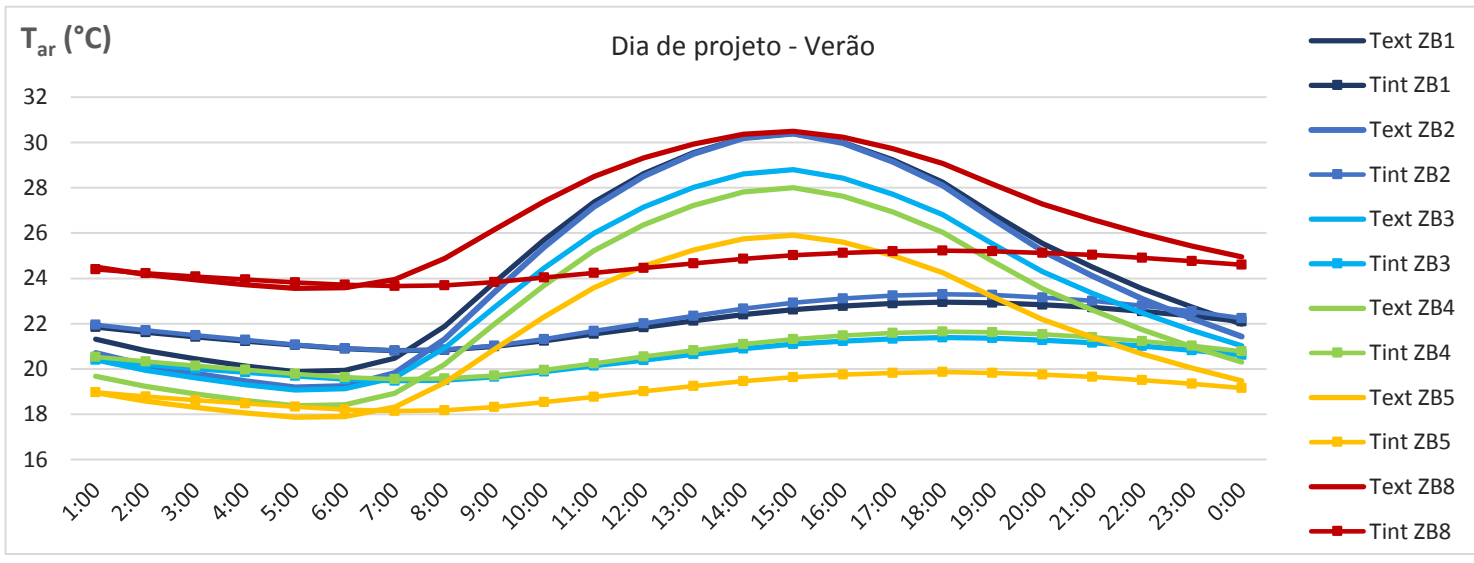

Esse resultado aparentemente satisfatório, poderia indicar que o sistema construtivo da edificação em estudo é adequado para todos os climas brasileiros. Todavia, esse comportamento térmico ocorre devido à uma limitação do tipo de simulação defindo pela Norma e não por causa do sistema construtivo escolhido. Conforme explicado no próprio manual do programa (DOE, 2013), as simulações com dia de projeto não devem ser utilizadas para avaliação do desempenho de uma edificação.

Ao se realizar a simulação utilizando a simulação com arquivo climático para as 8760 horas de um ano típico, observa-se que o comportamento térmico não é tão satisfatório. As Figura 3 e 4 apresentam a variação horária da temperatura do ar interna e externa para os meses mais quentes do ano, para Maringá e João Pessoa, respectivamente. As figuras ainda apresentam destacado a temperatura de conforto, calculada pelo software, para a zona estudada, conforme os critérios da ASHRAE Standart 55.

Figura 3 - Temperatura do ar interna e externa, no mês de dezembro (período extremo quente), para Maringá, Zona Bioclimática 1

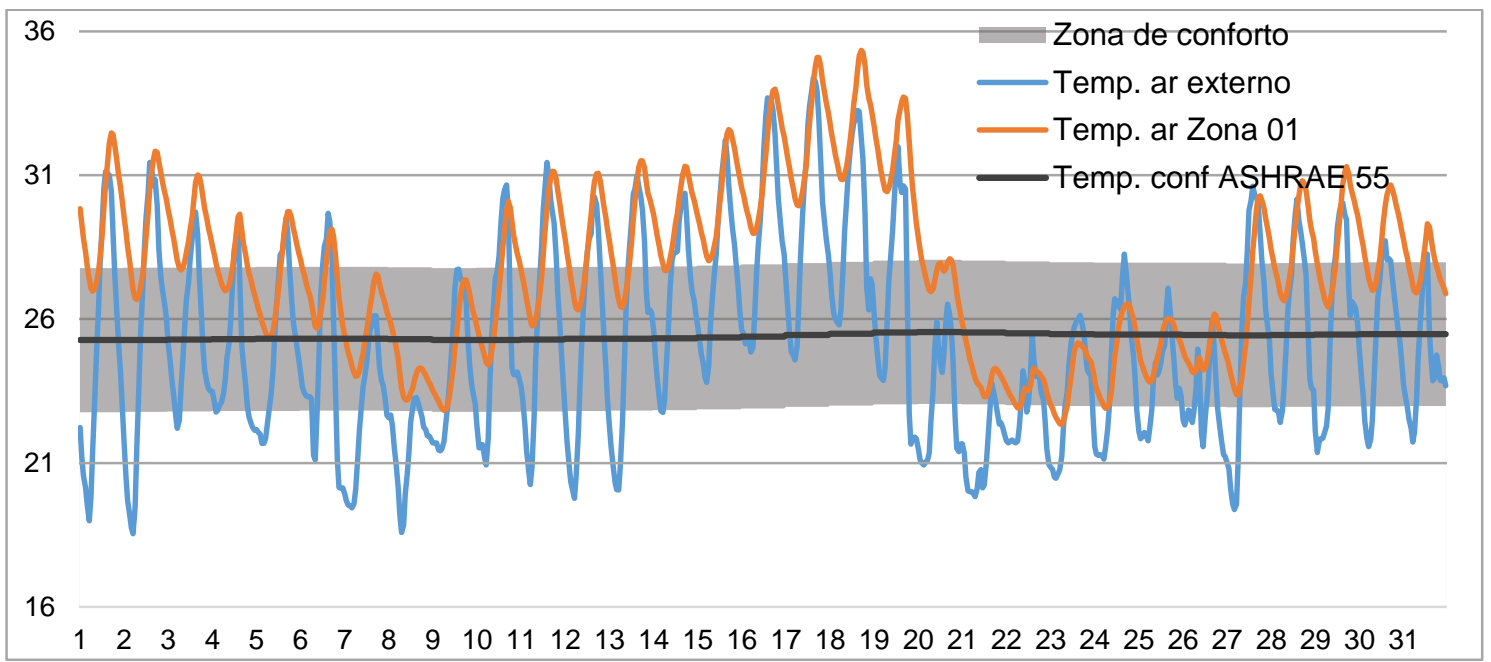

Figura 4 -Temperatura do ar interna e externa, no mês de janeiro (período extremo quente), para João Pessoa, Zona Bioclimática 8 


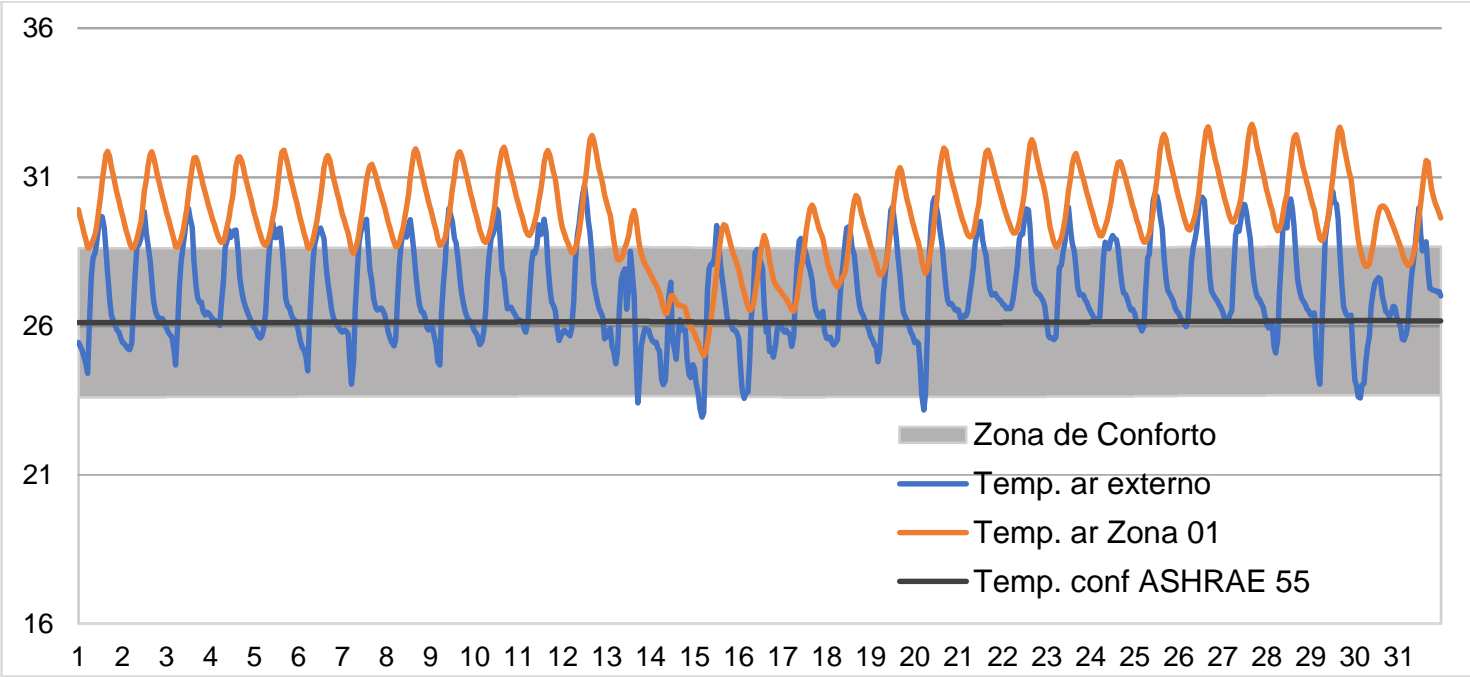

Em ambas figuras, a temperatura do ar interna tende a ser superior à externa, principalmente durante os horários de pico da temperatura. Além disso, a temperatura do ar interna tende a ser bem superior à temperatura de conforto. O desempenho horário é apresentado apenas para duas cidades, por uma limitação no tamanho do artigo, entretanto, esse comportamento térmico se repete nas demais cidades. Assim, se for considerada a simulação horária da temperatura, a edificação não alcançaria nem o desempenho mínimo estabelecido na NBR15.575, em nenhuma das Zonas Bioclimáticas.

De acordo com os parâmetros da ASHRAE Standard 55 (2010), é apresentado no Quadro 5 a distribuição da ocorrência temperatura do ar, conforme sensação térmica e a aceitabilidade de 80 e $90 \%$. As três primeiras colunas referem-se à temperatura do ar exterior e indicam a condição de conforto térmico fora da edificação. As colunas seguintes referem-se à temperatura operativa dentro da zona térmica 01 , que é o ambiente de ocupação permanente com pior orientação solar. As temperaturas do ar e operativa, assim como os limites foram calculados pelo software.

\section{Quadro 5 - Percentual de horas por sensação de estresse térmico, para a temperatura do ar externo e interno, da zona estudada}

\begin{tabular}{|l|c|c|c|c|c|c|c|c|c|c|}
\hline & & \multicolumn{3}{|c|}{ Ext. $80 \%$ aceitab. } & \multicolumn{3}{c|}{$80 \%$ de aceitabilidade } & \multicolumn{3}{|c|}{$90 \%$ de aceitabilidade } \\
\cline { 3 - 11 } Cidade & ZB & Frio & Calor & Conf. & Frio & Calor & Conf. & Frio & Calor & Conf. \\
\hline Maringá & 1 & $19 \%$ & $22 \%$ & $59 \%$ & $14 \%$ & $20 \%$ & $65 \%$ & $18 \%$ & $30 \%$ & $52 \%$ \\
\hline Santa Maria & 2 & $17 \%$ & $20 \%$ & $63 \%$ & $1 \%$ & $28 \%$ & $70 \%$ & $4 \%$ & $42 \%$ & $54 \%$ \\
\hline Belo Horizonte & 3 & $17 \%$ & $20 \%$ & $63 \%$ & $1 \%$ & $28 \%$ & $70 \%$ & $4 \%$ & $42 \%$ & $54 \%$ \\
\hline São Carlos & 4 & $19 \%$ & $22 \%$ & $59 \%$ & $26 \%$ & $4 \%$ & $70 \%$ & $38 \%$ & $9 \%$ & $54 \%$ \\
\hline Guaramiranga & 5 & $0 \%$ & $7 \%$ & $93 \%$ & $9 \%$ & $0 \%$ & $91 \%$ & $31 \%$ & $0 \%$ & $69 \%$ \\
\hline Barra & 6 & $24 \%$ & $24 \%$ & $53 \%$ & $0 \%$ & $55 \%$ & $45 \%$ & $0 \%$ & $70 \%$ & $30 \%$ \\
\hline Palmas & 7 & $16 \%$ & $20 \%$ & $64 \%$ & $0 \%$ & $35 \%$ & $65 \%$ & $1 \%$ & $50 \%$ & $50 \%$ \\
\hline João Pessoa & 8 & $3 \%$ & $1 \%$ & $96 \%$ & $0 \%$ & $38 \%$ & $62 \%$ & $0 \%$ & $57 \%$ & $43 \%$ \\
\hline
\end{tabular}

Por esse quadro, considerando aceitabilidade de $80 \%$, a média de horas de conforto térmico está entre 60 e $70 \%$ das horas, em todas as cidades, com exceção de Guaramiranga e Barra. As cidades das zonas 6 a 8 têm maior percentual de horas de desconforto por calor, que as cidades das zonas 1 a 3 , enquanto que as das zonas 4 e 5 praticamente não têm horas de desconforto por calor. 
Ponderando que $10 \%$ das horas equivalem à 2,4 horas em um dia e 36 dias em um ano, considerou-se ser aceitável esse o tempo máximo de desconforto. Esse valor foi estabelecido avaliando que durante este período, em razão do desconforto, haveria o uso do condicionamento de ar e consequente aumento do consumo de energia. Observa-se que, com exceção das cidades de São Carlos e Guaramiranga, todas as demais possuem um período de tempo em desconforto por calor superior a $10 \%$, indicando um potencial uso demasiado de ar condicionado. Além disso, observa-se que em quase todas as cidades há um aumento do número de horas de desconforto por calor em comparação com o clima exterior. Esse aumento é mais significativo nas cidades de climas mais quente, zonas bioclimáticas 6 a 8 .

Por fim, é apresentado o resultado do consumo do ar condicionado, para cada cidade, obtido das simulações com o EnergyPlus. A Figura 6 mostra a variação do consumo do sistema Split, por mês, e o Quadro 6, o consumo anual total, em kWh, para as mesmas cidades. Destaca-se que não foi simulado a cidade de Guaramiranga, ZB 5, por não ter sensação de desconforto por calor. Barra, Palmas e João Pessoa foram as que apresentaram maior consumo do sistema de ar condicionado, nessa ordem, mas os meses de maior consumo ocorrem em diferentes épocas do ano. Nas cidades das zonas 1 e 2 , houve um consumo significativo do ar nos meses de verão.

Figura 6 - Consumo mensal do ar condicionado, em $\mathrm{kWh}$, por Zona Bioclimática

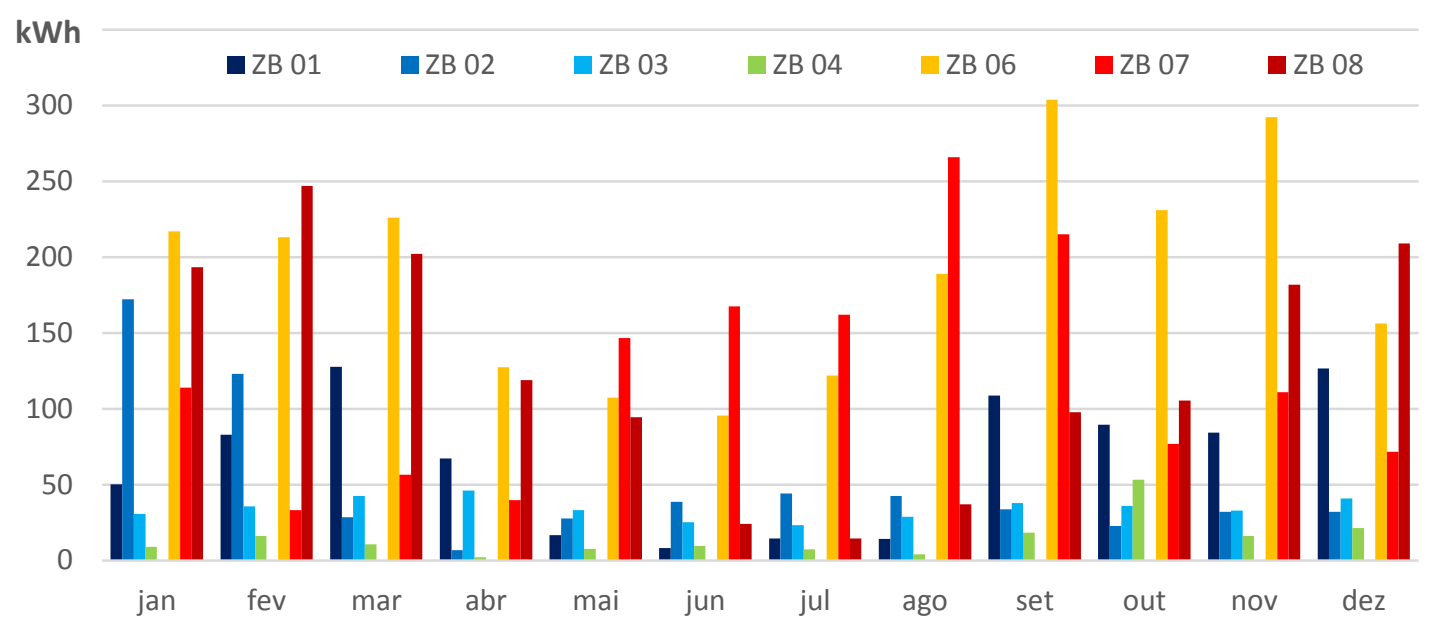

Quadro 6 - Consumo anual do sistema de ar condicionado, em kWh

\begin{tabular}{|c|c|c|c|c|c|c|c|c|}
\hline & ZB 01 & ZB 02 & ZB 03 & ZB 04 & ZB 05 & ZB 06 & ZB 07 & ZB 08 \\
\hline Ano & 791 & 605 & 413 & 175 & 0 & 2281 & 1461 & 1526 \\
\hline
\end{tabular}

\section{CONSIDERAÇÕES FINAIS}

A Norma NBR 15.575 tem por objetivo estabelecer um desempenho mínimo para edificações residenciais. No que contempla o desempenho térmico, a Norma estabelece que, no método de simulação, a temperatura interna das zonas de permanência prolongada deva ser no mínimo inferior à temperatura externa para o dia típico de verão e no mínimo superior em $3^{\circ} \mathrm{C}$ à temperatura externa para o dia típico de inverno. Contudo, esse tipo de abordagem não se mostra a mais apropriada para garantir o conforto térmico do usuário. 
Assim, o objetivo deste artigo é analisar o comportamento térmico dos sistemas construtivos utilizados em uma edificação multifamiliar, visando a garantia de maior conforto de seus usuários e menor consumo de energia para condicionamento artificial das edificações. Para tal foram realizadas simulações em 8 cidades brasileiras, cada uma pertencente a uma zona bioclimática: Maringá (ZB1), Santa Maria (ZB2), Belo Horizonte (ZB3), São Carlos (ZB4), Guaramiranga (ZB5), Barra (ZB6), Palmas (ZB7), João Pessoa (ZB8).

Os resultados apontaram que mesmo quando a Norma classifica a edificação como apresentando desempenho superior, na verdade as condições de conforto não são atingidas segundo a ASHRAE 55. Apesar de um desempenho satisfatório para os critérios de desempenho da norma nacional, a edificação resultou em períodos longos de desconforto e, consequentemente, uso de ar condicionado em todas as zonas bioclimáticas, com exceção das zonas 4 e 5 .

Essa incoerência é provavelmente decorrência da metodologia proposta pela Norma, considerando a simulação de dia típico, mesmo quando no próprio manual do programa é exposto que as simulações com dia de projeto são simplificadas e não devem ser utilizadas para avaliação do desempenho de uma edificação. Além disso, os parâmetros de simulação de um dia típico estão apenas parcialmente descritos na Norma, ficando a critério do simulados definir aqueles dados faltantes. Essas limitações da Norma poderão levar a um grande impacto no consumo do ar condicionado, que poderia ser reduzido caso as edificaçoes pudesse garantir no mínimo, um nível de conforto equivalente ao do clima externo.

\section{AGRADECIMENTOS}

Os autores gostariam de agradecer o apoio financeiro da Coordenação de Aperfeiçoamento de Pessoal de Nível Superior, CAPES, o Conselho Nacional de Desenvolvimento Científico e Tecnológico, CNPQ e o Centro de Pesquisa e Inovação Sueco-Brasileiro, CISB e da Saab AB"

\section{REFERENCIAS}

AMERICAN SOCIETY OF HEATING, REFRIGERATING AND AIR-CONDITIONING ENGINEERS (ASHRAE). ASHRAE Standard. 55: Thermal environmental conditions for human occupancy. Atlanta, 2010.

ASSOCIAÇÃO BRASILEIRA DE NORMAS TÉCNICAS (ABNT). NBR 15.220: Desempenho térmico de edificações. Rio de Janeiro, 2005.

ASSOCIAÇÃO BRASILEIRA DE NORMAS TÉCNICAS (ABNT). NBR 15.575: Edificações Residenciais - Desempenho. Rio de Janeiro, 2008.

BRASIL. Ministério das Cidades. Política Nacional de Habitação. Brasília, 2004.

U.S. Department of Energy, DOE. Ernest Orlando Lawrence Berkeley National Laboratory. EnergyPlus InputOutputReference. Set. 2013

FERREIRA, C. C., PEREIRA, I. M. Avaliação do Desempenho Térmico de Habitação de Interesse Social de Acordo com a NBR 15575, para as Diversas Zonas Bioclimáticas In: XIV Encontro Nacional de Tecnologia do Ambiente Construído, 2012, Juiz de Fora. Anais... Juiz de Fora: ANTAC / UFJF, 2012. 